\title{
Structural Health Monitoring of a Frame Using Random Vibration Analysis
}

\author{
Aneesha S Das ${ }^{1}$, Dr. Sajal Roy ${ }^{2}$, Ritzy .R ${ }^{3}$ \\ ${ }^{1}$ PG Scholar, Structural Engineering, SBCE \\ ${ }^{2}$ Scientist D, Research and Development Engineers, DRDO, PUNE \\ ${ }^{3}$ Assistant Professor, Department of Civil Engineering, SBCE
}

\begin{abstract}
In the past few years, the thin walled structure comprises an important and growing proportion of engineering construction industry. Their areas of applications increasingly ranging from aircraft, bridges, industrial buildings, warehouses, exhibition pavilions, concert halls, sport arenas, ships, oil rigs to storage vessel. They have a high load carrying capacity despite of their small thickness. The design calculation required to estimate the strength, stability and vibration of thin walled structure are among the most complex problems encountered in structural design. Dynamic testing of full scale steel frame structure is not possible because the damage may be so strong that it will be impossible to retrofit the frame building for it further using. Dynamic testing of a relatively small part of building (having the same structural scheme) is one of the possible ways for the solution of the above described problem. Before the dynamic testing is done, dynamic analysis of full scale and the small scale are carried out using ANSYS software for preliminary study about the vibration characteristics of the structure for its design consideration. This paper presents the structural health monitoring of a portal steel frame using transient vibration analysis which is followed by random analysis. The purpose of this paper is to present the result of an analytical study on an finite element method for damage detection of loosened bolt connections. For this, a laboratory specimen in the form of a portal frame is taken into consideration.The structure consist of a one bay frame, on which transient analysis followed by random vibration analysis is carried out. The accelerations data are measured for six different locations near the lap connections. Two states of structure are considered: a healthy state and damaged one. The damage simulation is introduced by the means of loosening one out of two bolts alternatively at one of lap connections. The result focuses on the detection and localisation of structural damages such as loosened bolt, which usually causes a local reduction in stiffness. The method uses the comparison of natural frequencies and vibration energy from both healthy and damaged state obtained through Fast Fourier Transform (FFT) and analysis. It was observed that there is deviation in natural frequency and vibration energy of response obtained due to reduction in stiffness which indicates the presence of damage. There is a scope to extend the same work on composite plate structure.
\end{abstract}

Keywords: Portal frame, Finite element method (FEM), Mode shapes, Natural frequencies, Fast Fourier transforms, Damage detection etc.

\section{Introduction}

The structural health monitoring (SHM) revolution is benefiting from rapid advances in sensor and dataacquisition technologies. Development of various methods for non-destructive evaluation and condition monitoring has intensified in the past several decades. Implementation of those methods and procedures are geared towards reducing maintenance costs and increasing operational safety of different structures. Damages in structures generally involves cracking, delaminating of composite layers, and loosened fasteners. Detection of damage is based on sensing and detecting changes in vibration characteristics of structures. Various damage detection methods have been developed, which operate on data in time, frequency, and modal domains. In large built-up structures vibration introduces local stiffness changes that affect global vibration characteristics of the structure. Noise and vibration in the structure are caused by particular processes where dynamic forces excite structures. The term vibration describes repetitive motion that can be measured and observed in a structure. Unwanted vibration can cause fatigue or degrade the performance of the structure. Therefore it is desirable to eliminate or reduce the effects of vibration by studying the vibration characteristics of the structure.
Vibration analysis is divided into sub-categories such as free vs. forced vibration, sinusoidal vs. random vibration, and linear vs. rotation-induced vibration. This paper are focuses on modal, transient and random vibration analysis method for evaluating vibration characteristics of the structure. The technique uses the finite element analysis using ANSYS 12.1 to obtain the response of the structure under modal, transient and random vibration.To study the response, the fast fourier transform of the response signal is taken and the interpretation is made on deviation in natural frequency of the healthy and damaged structure. Simulation is done by loosening of bolt .Response is obtained for both healthy and damaged state.

\section{Literature Survey}

[1]Bartlomiej Blachowski, Andrzej Swiercz,Nikos Pnevmatikos(2015)

They conducted an experimental verification of existing techniques for localization of a loosened bolted connection. Experimental modal analysis reveals that the loosened bolts in the connection cause a shift only in some of the frame's natural frequencies, while the others remain insensitive to the damage.

[2] Webb, G., Vardanega, P. J., Fidler, P., \& Middleton, C. (2014) 


\section{International Journal of Science and Research (IJSR) \\ ISSN (Online): 2319-7064 \\ Index Copernicus Value (2013): 6.14 | Impact Factor (2015): 6.391}

The results of the literature survey are used to propose a categorization system to better assess the potential outcomes of bridge SHM deployments. It is shown that SHM studies can be categorized as one (or a combination) of the following: (1) anomaly detection, (2) sensor deployment studies, (3) model validation, (4) threshold check, and (5) damage detection.

\section{[3]Michael Dohler, Falk Hille (2014)}

Damage detection can be performed by detecting changes in the modal parameters between a reference state and the current (possibly damaged) state of a structure from measured output-only vibration data.

\section{[4]Cilmar D. Basaglia, Dinar R.Z. Camotim, Humbert.B} Coda (2013)

Cilmar D.Basaglia and two other carried out an investigation on the use of GBT(Generalised Beam Theory) to analyse the vibration behaviour of thin-walled steel frames. The presentation and discussion of numerical results concerning the local, distortional and global vibration behaviour of loadfree and loaded symmetric portal frames are carried on. The study focused on the influence of the applied load level on the vibration frequencies and mode shapes.For validation purposes, most of the GBT-based results were compared with values obtained by means of shell finite element analyses carried out in the code ANSYS. An excellent agreement was found in all cases, despite the large difference between the numbers of d.o.f involved in the two analyses.

\section{[5]Oleg V. Shiryayev, Joseph C. Slater (2014)}

This article describes detection of structural damage using statistical properties of randomdec signatures. Proposed technique is model free and does not require input measurements. The technique is evaluated using acceleration data obtained from a finite element model of a frame-like structure.

\section{Objective of work}

- To carry out non destructive assessment of failure probability of structure subjected to impulse and random loads.

- Application of various vibration analysis such as modal analysis, transient analysis and random vibration analysis and to check its feasibility in damage detection.

- To perform transient analysis of a steel frame subjected to impulse load.

- To develop MATLAB program for frequency response function to observe the deviation in natural frequency due to damage.

- To perform random vibration analysis on portal frame and to damage simulation .

\section{Methodology}

The methodology of work consist of

1) Preliminary study of ANSYS software, free vibration, transient vibration, random vibration.
2) Modeling of one bay portal frame in ANSYS and conduct modal analysis to obtain natural frequency and mode shapes.

3) Validation of software.

4) Conduct transient analysis to obtain fundamental frequency and to study the response through FRF obtained in MATLAB.

5) Simulate the damage by intact the bolt alternatively at one lap connection and conduct transient analysis and study the response through FRF obtained in MATLAB.

6) Conduct the random vibration analysis and study the response through FRF obtained in MATLAB.

7) Simulate the damage by intact the bolt at lap connection and conduct the random vibration analysis to study the response.

8) Intepreate the result.

\section{Finite Element Analysis}

\subsection{Model description}

Finite Element Analysis is a computational tool for performing engineering analysis. The solution of very complex systems as geometrical scale or an equation can be made with ANSYS programme. ANSYS APDL 12.1 application gives very close results to experimental results in the determination of mode shapes, natural frequencies of the one bay portal steel frame subjected to modal analysis. By using the modelling software ANSYS APDL 12.1, the frame is modelled with 3D Elastic4 beam element and shell element (Shell 63). The frame is modelled as a 3D structure consisting two columns and a beam.

\subsection{Modelproperties}

A material's response is determined by the material properties assigned to the part. Structural steel is the material chosen and by default the material properties are given in Table1.

Table 1:Material properties of steel

\begin{tabular}{|c|c|}
\hline Density & $7.8 \times 10^{-9}$ ton $/ \mathrm{mm}^{3}$ \\
\hline Young's modulus & $2.1 \times 10^{5} \mathrm{~N} / \mathrm{mm}^{2}$ \\
\hline Poison ratio & 0.3 \\
\hline
\end{tabular}

\subsection{Attach geometry}

Define the Key points and join and provide the geometrical properties and material properties. Geometrical properties of the structural model are provided in Table 2.

Table2: Geometric properties of structural model

\begin{tabular}{|c|c|c|c|c|}
\hline \multirow{2}{*}{ S.No } & \multirow{2}{*}{ Parts } & \multicolumn{3}{|c|}{ Dimension in mm } \\
\cline { 3 - 5 } & & Thickness $(d)$ & Width $(b)$ & Length $(L)$ \\
\hline 1 & Column & 5 & 100 & 450 \\
\hline 2 & Beam & 5 & 100 & 400 \\
\hline
\end{tabular}

The frame is modelled as a 3D structure consisting of beam and columns. Beam and shell elements are used to model the frame. The element types used are 3D elastic 4 beam. For 3D surface bodies, element type used is SHELL 63.Loads and supports are applied on the basis of the type of analysis. Fixed support is applied at the base. 


\section{International Journal of Science and Research (IJSR) \\ ISSN (Online): 2319-7064 \\ Index Copernicus Value (2013): 6.14 | Impact Factor (2015): 6.391}

Translational degree of freedom UX, UY, UZ and rotational degree of freedom RX, RY, RZ are constrained at the base.

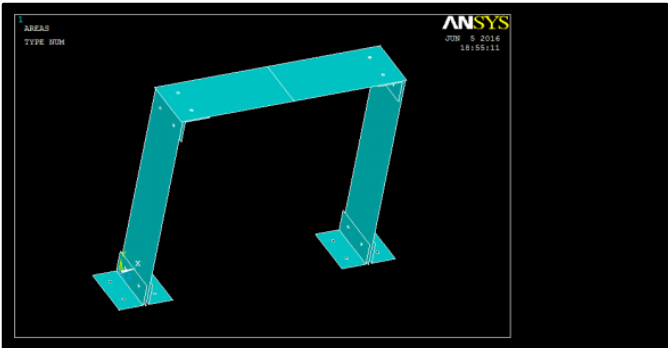

Figure1: Modelled frame

\section{Modal analysis}

Modal analysis is a type of analysis used to determine the structures vibration characteristics. It is the most fundamental of all dynamic analysis types. In this case, Modal analysis is choose to determine the natural frequencies and mode shapes of an one bay portal steel frame to determine mode shapes and natural frequencies.

The modal analysis is done on the portal frame given in the figure2.Free vibration analysis is conducted. Block Lanczos Mode Extraction method is used to solve and obtain the mode shapes and corresponding natural frequencies for the first 6 modes

Table 3 shows the analysis results and the mode shapes obtained are shown in Fig.2.

Table 3: Analysis result

\begin{tabular}{|c|c|}
\hline Mode & Frequency $(\mathrm{Hz})$ \\
\hline 1 & 15.976 \\
\hline 2 & 83.307 \\
\hline 3 & 94.487 \\
\hline 4 & 118.092 \\
\hline 5 & 119.232 \\
\hline 6 & 133.447 \\
\hline
\end{tabular}

\subsection{Mode Shapes}

Modes are used as a simple and efficient means of characterizing resonant vibration. Resonant vibration is caused by an interaction between the inertial and elastic properties of the materials within a structure. Resonant vibration is often the cause of, or at least a, contributing factor to many of the vibration related problems that occur in structures. To better understand any structural vibration problem, the resonances of a structure need to be identified and quantified. A common way of doing this is to define the structure's modal parameters. The following are the first two mode shapes of the modal analysis.

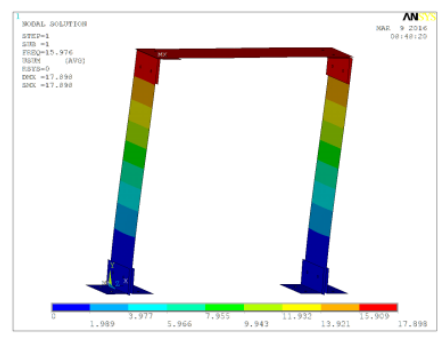

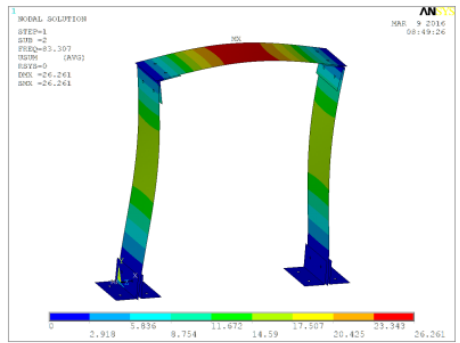

Figure 2: Mode shapes

\section{Mathematical Formulation}

A system is said to undergo free vibration when it oscillates only under an initial disturbance with no external forces acting afterward.
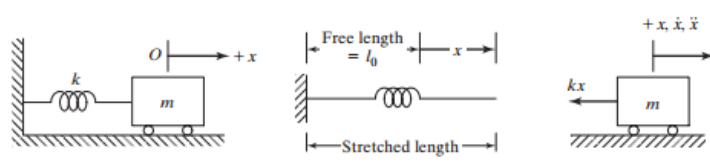

Figure 3: Spring mass system

Figure 3 shows a spring-mass system that represents the simplest possible vibratory system. It is called single degree of freedom system, since one coordinate $(\mathrm{x})$ is sufficient to specify the position of the mass at any time. There is no external force applied to the mass; hence the motion resulting from an initial disturbance will be free vibration.
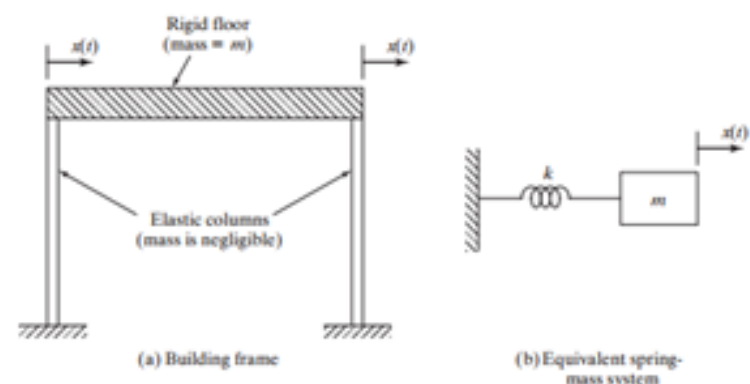

Figure 4: Idealisation of a building frame

Since there is no element that causes dissipation of energy during the motion of the mass, amplitude of motion remains constant with time; it is an undamped system. The study of the free vibration of undamped and damped single degree of freedom systems fundamental to understanding of more advanced free vibrations.

Several mechanical and structural systems can be idealised as single degree of freedom system. In many practical system, the mass is distributed throughout the system can also be idealised by a single spring. The building frame shown in figure 4 can also be idealized as a spring mass system in figure 4 .In this case the spring constant $K$ is merely the ratio of force to deflection .It can be determined by the geometric and material properties of the column. The mass of the idealised system is the same as that of floor if we assume the mass of the column to be negligible. 


\section{International Journal of Science and Research (IJSR) \\ ISSN (Online): 2319-7064}

Index Copernicus Value (2013): 6.14 | Impact Factor (2015): 6.391

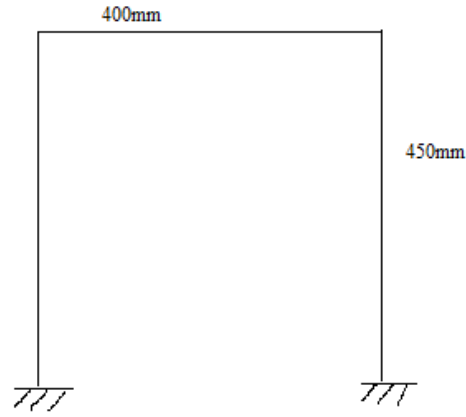

Figure 5: Portal frame specimen

The density of the structural steel is give by

$=7800 \mathrm{~kg} / \mathrm{m}^{3}$

$=7800 \times 10^{-12}$ ton $/ \mathrm{mm}^{3}$

$\mathrm{M}=\rho \times \mathrm{v}$

Mass $=$ density $\mathrm{x}$ volume

Mass of the structure $=$ mass of beam + mass of column

$=\left(7.8 \times 10^{-9} \times 400 \times 100 \times 5\right)+\left(7.8 \times 10^{-9} \times 2 \times 450 \times 100 \times 5\right)$

$=0.0051$ ton

Moment of inertia $\mathrm{I}=\mathrm{bd}^{3} / 12=\left(100 \times 5^{3}\right) / 12$

$=1.041 \times 10^{3} \mathrm{~mm}^{4}$

$\mathrm{K}=2 \times 12 \mathrm{EI}=\left(2 \times 12 \times 2.1 \times 10^{5} \times 1.041 \times 10^{3}\right) /(450)^{3}$

$\mathrm{L}^{3}=57.5 \mathrm{~N} / \mathrm{mm}$

Frequency $=(1 / 2 \pi) \sqrt{ }(\mathrm{K} / \mathrm{m})$

$=(1 / 2 \pi) \sqrt{ }(57.5 / 0.0051)$

$=16.8 \mathrm{~Hz}$

The mathematical and software results are compared for software validation and it has shown that first frequency value of modal analysis is approximately near to the mathematical formulation and hence we can conclude that the software is validated for carrying out further analysis.

\section{Transient Analysis}

Transient analysis is a type of structural analysis in which the structure is subjected to dynamic (actions having high acceleration) loading is studied .For example transient events like an impulse loading such as an earthquake. Result of structural part dynamic analysis can be used for prognosis of damage progress in full scale buildings. It allows preventing of formation of cracking, loosened fasteners and estimation of building ability to withstand impulse loads. The choice of excitation technique will depend on the structure, the application and quality required of measured data and any future analysis on the data. The requirements for a transient structural response analysis vary from one application to another. For some analyses a single-degreeof-freedom (SDOF) model is sufficient, whilst in other cases a more detailed multi-degree-of-freedom (MDOF) model is necessary. This analysis deals with applying impulse force whose duration is short compared with the upper cut-off frequency of the system so as to simulate an impulse.The excitation of $50 \mathrm{~N}$ impulse forces is applied to the portal frame structure in $\mathrm{x}$ direction near to the bolted connections. The impulse excitation is provided for a short period of 2 seconds. The transient response is obtained for six locations at the portal steel frame. The acceleration time history graph are obtained for the six locations out of which one is shown below in figure 6 .

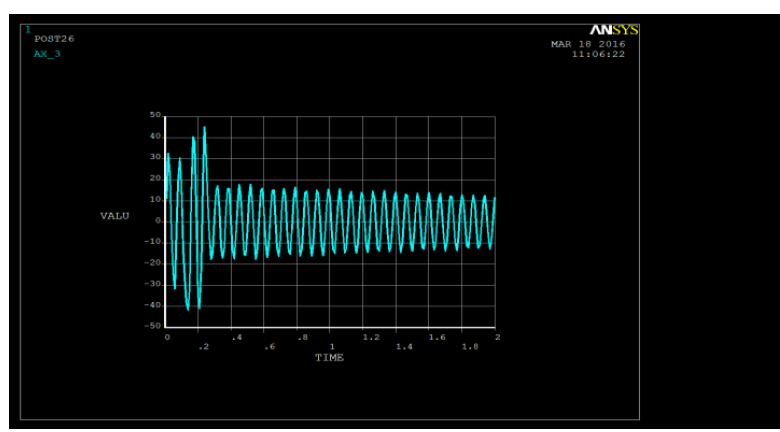

Figure 6: AccelerationTime Graph

The acceleration time graph plot is obtained for that six location and the fast fourier transform(FFT) of six responseis obtained in MATLAB.The Fast Fourier Transform is mainly done to study the response signal which tells about what frequencies are present in the signal and in what proportions.

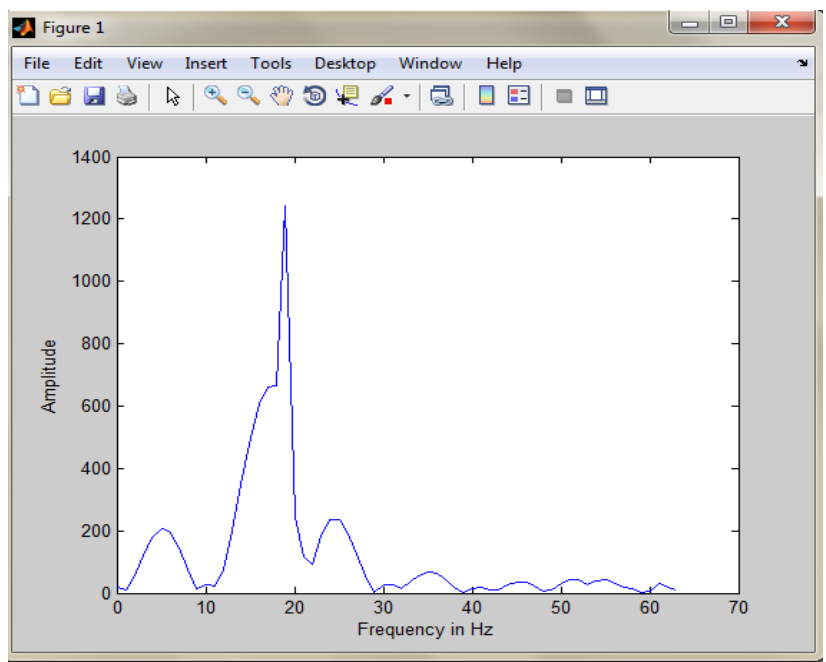

Figure 7: FFT of a transient response

The FFT of a transient response shows that the first fundamental or harmonic peak frequency is nearer to some what $19 \mathrm{~Hz}$ and the second harmonic peak is closer to $17 \mathrm{~Hz}$ which is approximately equal to fundamental frequency obtained in modal analysis. Therefore FFT graph suggest that the structure vibratemore at its fundamental frequency when an impluse forceis applied for a short period of time. Similarly remaining five FFT graph is obtained for other five responses.

\subsection{Damage Simulation}

The structural health monitoring of frame is done analytically by simulating damage i.e loosening and intacting bolt alternatively at the left bolted lap connection.

The damage is simulated on frame by loosening left bolt of left lap connection, by keeping right bolt intact vice versa and is followed by transient analysis. The response is taken for six location of the steel frame. The acceleration time history graph is obtained for six locations after damage simulation.

The fast fourier Transform of the six response signal are performed in MATLAB and is given below in figure10. 


\section{International Journal of Science and Research (IJSR) \\ ISSN (Online): 2319-7064}

Index Copernicus Value (2013): 6.14 | Impact Factor (2015): 6.391

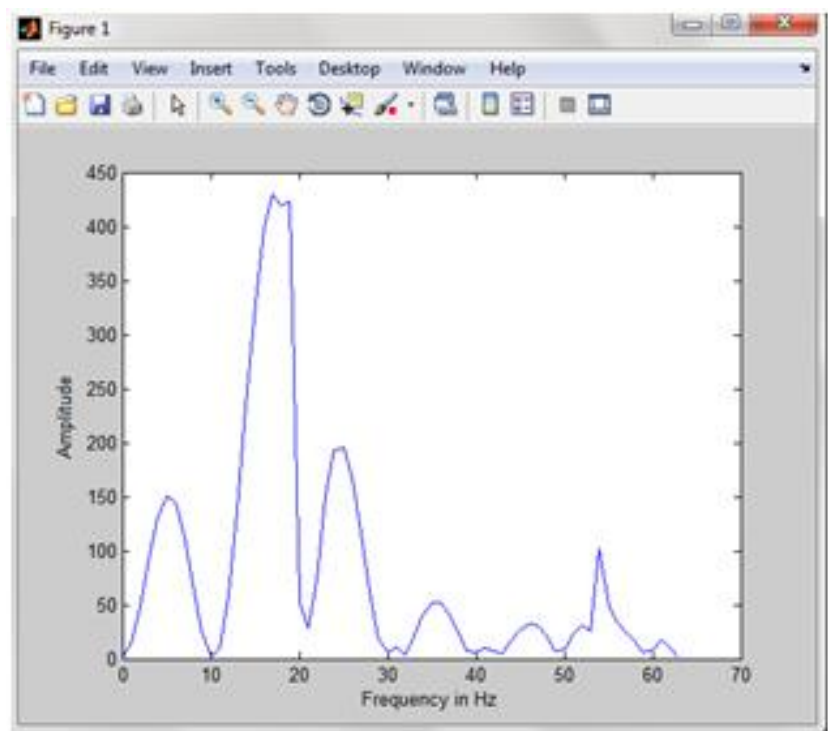

Figure 8: FFT of a simulation response

The fast fourier transform of the simulation response so obtained indicate that there is decrease in fundamental frequency or the first harmonic peak frequency in the above figure 10 .The first fundamental frequency is reduced from $19 \mathrm{~Hz}$ to $17 \mathrm{~Hz}$.The reduction in fundamental frequency indicate that there is reduction in stiffness of the frame structure for both damage simulation. The damage is simulated on frame by loosening left bolt of left lap connection, by keeping right bolt intact vice versa and is followed by transient analysis. The response is taken for six location of the steel frame.

\section{Random Vibration Analysis}

The models used in dynamic analyses of structure are idealisation created to represent the response of real structure to various dynamic loads (strong earthquake shaking, strong winds, explosion etc).These model can be verified by conducting full scale ambient and forced vibration experiment.

A random vibration is one whose absolute value is not predictable at any point in time. As opposed to sinusoidal vibration, there is no well defined periodicity - the amplitude at any point in time is not related to that at any other point in time. Figure 2 shows the amplitude time history of a random vibration.

Random vibration can be represented in the frequency domain by a power spectral density function. The typical units are acceleration $\left[\mathrm{G}^{\wedge} 2 / \mathrm{Hz}\right]$ versus frequency $[\mathrm{Hz}]$.

Based on the random vibration response measurement made at various departments of energy facilities, a input power spectral density (PSD) in irregular amplitude over a frequency of 100 to $10000 \mathrm{~Hz}$ was considered as a representative of anticipated random vibration that frame structure will experience. Power Spectral Density defines the distribution of power over the frequency range of excitation. Source of random vibration include traffic and wind induced motion. The input or excitation is assumed to be act in nodal $\mathrm{x}$ direction.
The random vibration signal generated in MATLAB is given below in figure9

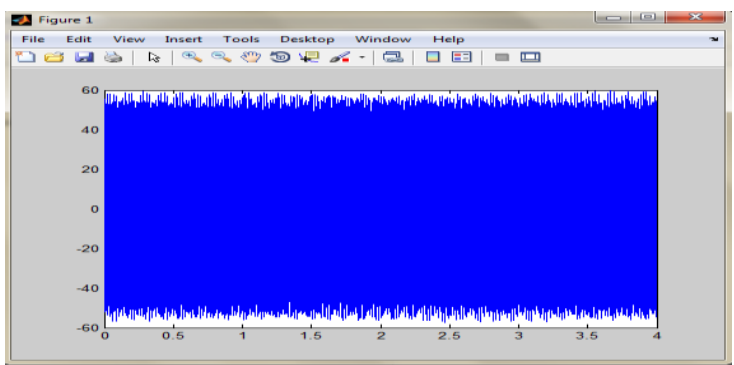

Figure 9: Random signal

The MATLAB code for generated random signal is given as follows.

$\mathrm{fs}=4096$

$\mathrm{t}=4$

$\mathrm{N}=\mathrm{f} \mathrm{s} * \mathrm{t}$

tt $=0: 1 / f s: t-1 / f s$

$x \operatorname{signal}=4 * \sin (2 * \mathrm{pi} * 100 * \mathrm{pi} * t t)+7 * 7 * \sin (2$

* $\mathrm{pi} * 980 * t \mathrm{t})+5 * \sin (2 * \mathrm{pi} * 1600 * t t)$;

$\mathrm{x}=2 *$ rand $(1, \mathrm{~N})+\mathrm{x}$ signal;

$\mathrm{Plot}(\mathrm{tt}, \mathrm{x})$

The power spectral density of the random signal is also generated in MATLAB is given below.

f $S=4096$;

$t=4$;

$\mathrm{N}=\mathrm{f} \mathrm{S} * \mathrm{t}$

tt $=0: 1 / \mathrm{fs}: \mathrm{t}-1 / \mathrm{fs}$;

$x \operatorname{signal}=4 * \sin (2 * \mathrm{pi} * 100 * \mathrm{pi}$ tt $)+7 * 7 * \sin (2$

$* \bar{p} i * 980 * t t)+5 * \sin (2 * \mathrm{p} i * 1600 * t t) ;$

$\mathrm{x}=2 *$ rand $(1, N)+\mathrm{x} \_$signal;

$\mathrm{Plot}(t t, \mathrm{x})$;

$\mathrm{x} \mathrm{k}=\mathrm{fft}(\mathrm{x}, \mathrm{N})$;

$\mathrm{K}=\mathrm{fs} / 2 *$ linspace $(0,1, \mathrm{~N} / 2+1)$;

Semilogy $(K, \operatorname{abs}(x k(1: N / 2+1)))$;

$\mathrm{x} \operatorname{psd} 1=2 * a b s(x \mathrm{k}(1: \mathrm{N} / 2+1)) \cdot{ }^{\wedge} 2$;

plot $(\mathrm{K}, \mathrm{x} \operatorname{psd} 1)$;

xlabel ('Hz');

ylabel ('psd $\left.\mathrm{g}^{\wedge} 2 / \mathrm{Hz}^{\prime}\right)$;

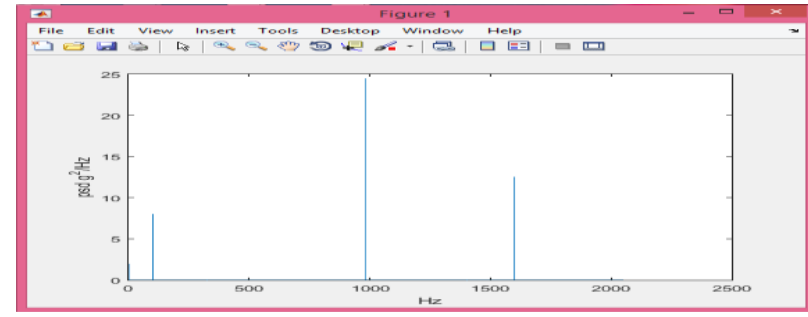

Figure 10: PSD of a random signal.

A power spectral density can be calculated for any type of vibration signal, but it is particularly appropriate for random vibration.So an input power spectral density synthesized from a random signal which is generated from random vibration is taken to provide excitation at the frame structure. The values of input power spectral density synthesized from the MATLAB are taken as the input for excitation in ANSYS software. The input PSD graph for the excitation is shown in figure 13 given below.

\section{Volume 5 Issue 6, June 2016 www.ijsr.net}




\section{International Journal of Science and Research (IJSR) \\ ISSN (Online): 2319-7064}

Index Copernicus Value (2013): 6.14 | Impact Factor (2015): 6.391

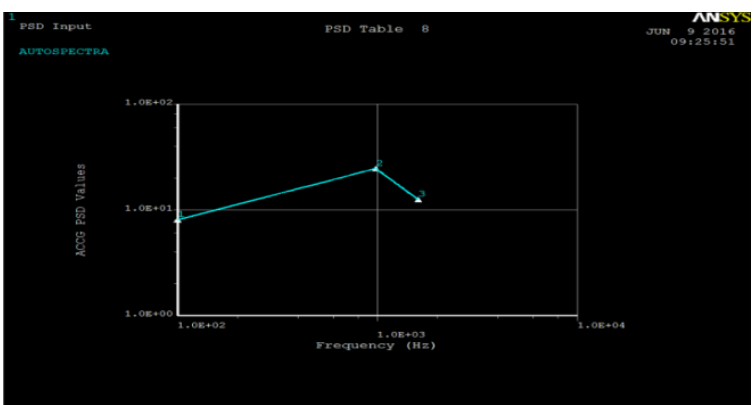

Figure11:An input PSD graph

The random vibration analysis is done through an excitation provided in the form of tabular input PSD values. The analysis is first performed on the frame without damage simulation .The excitation is provided in nodal $\mathrm{x}$ direction at the bolted lap connection. The PSD $\mathrm{G}^{\wedge} 2 / \mathrm{Hz}$ versus frequency values are obtained for six location of portal steel frame which is shown in Figure14.

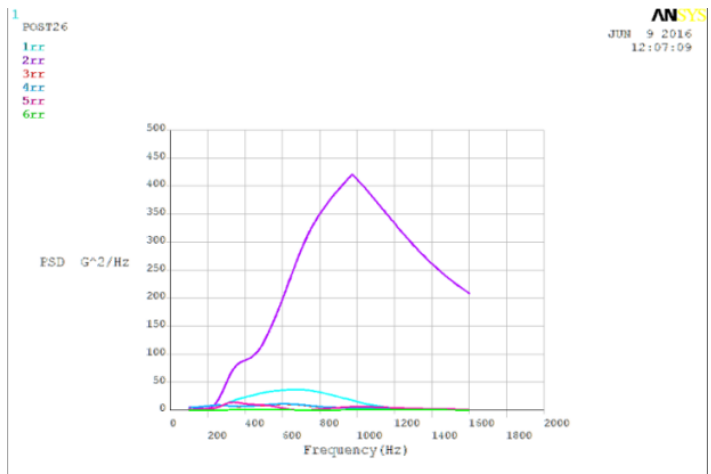

Figure12: $\mathrm{PSD} \mathrm{G}^{\wedge} 2 / \mathrm{Hz}$ versus Frequency Graph

The above graph gives six responses at six location of a portal frame which are named as $1 \mathrm{r} \mathrm{r}, 2 \mathrm{rr}, 3 \mathrm{rr}, 4 \mathrm{rr}, 5 \mathrm{rr}$ and $6 \mathrm{rr}$.

The excitation is provided in 2rr position near the bolted lap connection in $\mathrm{x}$ direction. Hence we can see from graph that vibration energy is more at the position $2 \mathrm{rr}$ as compared to other locations and the second position 1rr shows more vibration energy than other positions in the graph.

\subsection{Damage Simulation}

Damage simulation is done by loosening the bolt of right lap connection of portal frame .In right lap connection, left side bolt of connecting and outstanding leg are loosened alternatively and after that both are loosened. The excitation is provided at left lap connections in $\mathrm{x}$ direction. The response is taken for six location of the steel frame for all the three simulation.

\subsubsection{Damage simulation at left side connecting leg}

The bolt is loosened at the left side of the connecting leg and the excitation is provided at the left lap connection. The PSD versus frequency $(\mathrm{Hz})$ graph is obtained for six location of portal frame as shown in figure15. and the vibration energy of the response is studied.

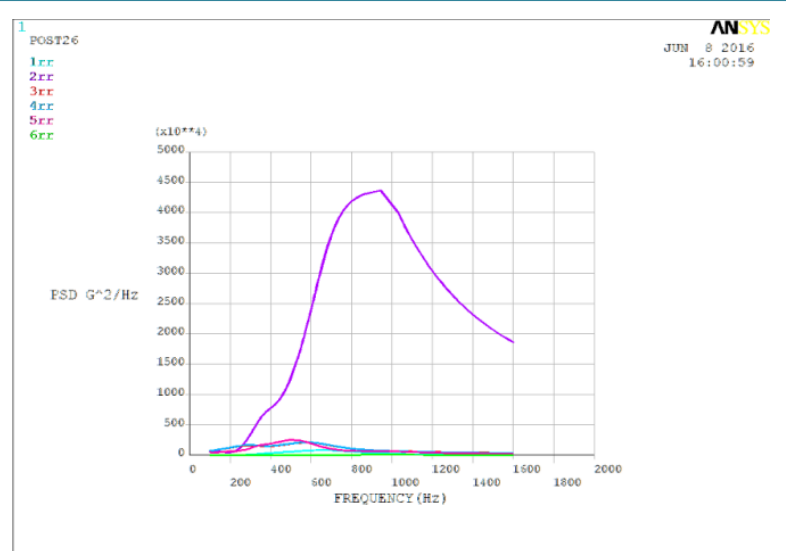

Figure13: Loosened left side bolt in connecting leg

The above PSD $\mathrm{G}^{\wedge} 2 / \mathrm{Hz}$ Vs $\mathrm{Hz}$ graph shows that vibration energy of the responses at the various position of the portal frame. From the figure it can be observed that at position $2 \mathrm{rr}$, vibration energy is decreased from earlier as compared to the vibration energy in healthy state response graph.The vibration energy of the responses at the position 3rr and 4rr are nearly same but slightly increased from its initial position as compared to vibration energy of healthy state response graph .The significant difference in vibration energy is observed at the location 4rr and 5rr which shows a increase in vibration energy as compared to vibration energy in healthy state response graph.

\subsubsection{Damage simulation at left side outstanding leg}

The bolt is loosened at the left side of the outstanding leg and the excitation is provided at the left lap connection. The PSD $G^{\wedge} 2 / H z$ versus frequency $(\mathrm{Hz})$ graph is obtained for six location of portal frame as shown in figure16 and the vibration energy of the response is studied.

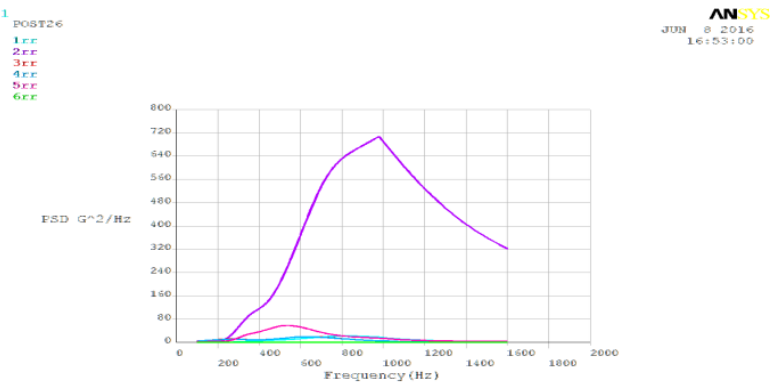

Figure15: Loosened left side bolt in outstanding leg

The above PSD G^2/Hz Vs $\mathrm{Hz}$ graph shows that vibration energy of the responses at the various position of the portal frame. From the figure it can be observe that vibration energy at position $2 \mathrm{rr}$ is always higher than that of remaining all position in the portal frame. A significant increase in vibration energy is observed at the position 5rr.Vibration energy at remaining all position rises to a certain range but comparatively low as compared to the position $2 \mathrm{rr}$ and $5 \mathrm{rr}$.

9.1.3Damage simulation at left side of both connecting and outstanding leg.

The bolt is loosened at the left side of both connecting and outstanding leg and the excitation is provided at the left lap 


\section{International Journal of Science and Research (IJSR) \\ ISSN (Online): 2319-7064 \\ Index Copernicus Value (2013): 6.14 | Impact Factor (2015): 6.391}

connection. The PSD $\mathrm{G}^{\wedge} 2 / \mathrm{Hz}$ versus frequency $(\mathrm{Hz})$ graph is obtained for six location of portal frame as shown in figure17and the vibration energy of the response is studied.

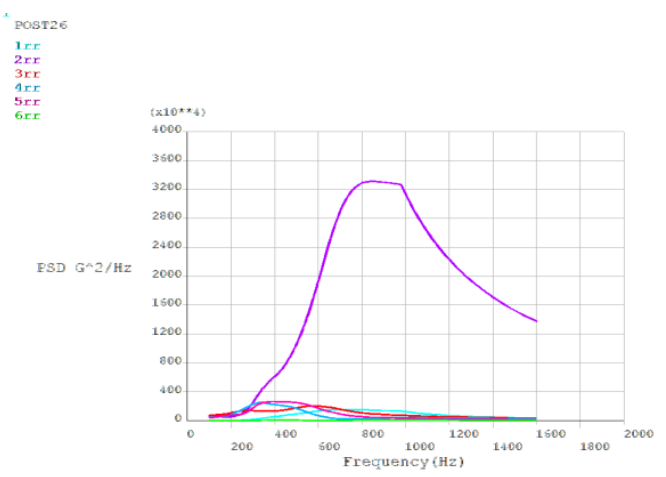

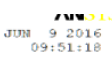

Figure14: Loosened left side bolt at both connecting and outstanding leg.

The above PSD G^2/Hz Vs $\mathrm{Hz}$ graph shows that vibration energy of the responses at the various position of the portal frame. From the figure it can be observe that the vibration energy of positions 1rr, 3rr, 4rr, 5rr and 6rr gives a sudden rise when the bolt is loosened at both connecting and outstanding leg. As usual the vibration energy at the position $2 \mathrm{rr}$ is highest of all. After the position 2rr, vibration energy is higher at position 5rr, 4rr, and 3rr in descending order.

\section{Statiscal Summary}

The following figures statistically explain about the responses of PSD $\mathrm{G}^{\wedge} 2 / \mathrm{Hz}$ Vs frequency $(\mathrm{Hz})$ obtained at six location of the portal frame.

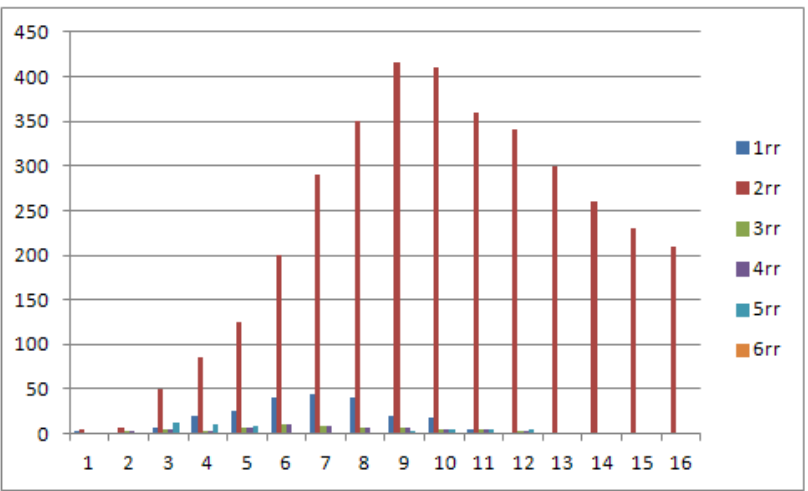

Figure16: Healthy state response

From the graph it can be concluded that that vibration energy of the response at the position $2 \mathrm{rr}$ is highest as compared to all other positions because excitation is provided at the $2 \mathrm{rr}$ position which lead to the increase in vibration energy of the frame at that position .Similarly vibration energy at the position 1rr is comparatively higher after 2rr position because the position 1rr lies in same side of applied excitation. Now the frame is subjected to three damage simulation for which Statiscal conclusions are made.

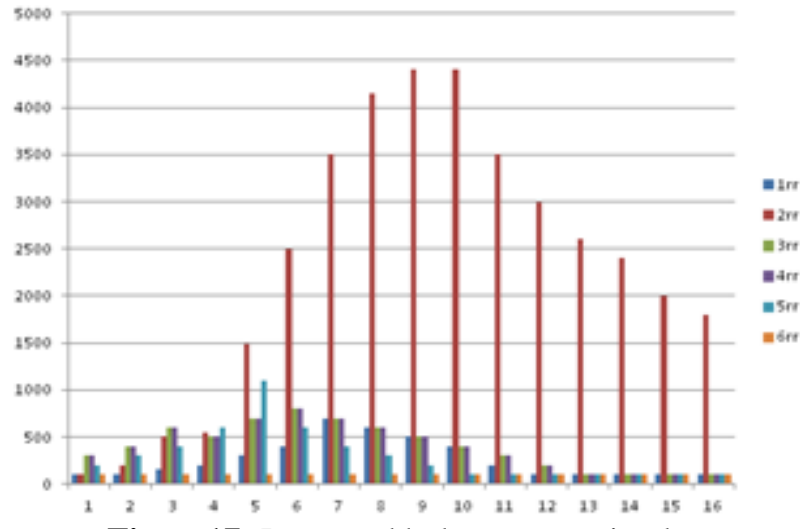

Figure17: Loosened bolt at connecting leg

From the above Fig.19 graph it was concluded that the vibration energy at the position $2 \mathrm{rr}$ remains highest of all.The second highest value was observed for position 5rr.Here it was also observed that vibration energy at the position 3rr and 4rr almost same and it is the third highest value after the position 5rr. But it was observed that vibration energy at the position 5rr shows a sudden increase which indicates the presence of damage at nearby location only. The sudden increase in vibration energy value at position 5rr indicates that there is the presence of damage at the location 4rr which results in the transfer of the energy to the position 5rr.Hence it is concluded that the damage is located at the position $4 \mathrm{rr}$.

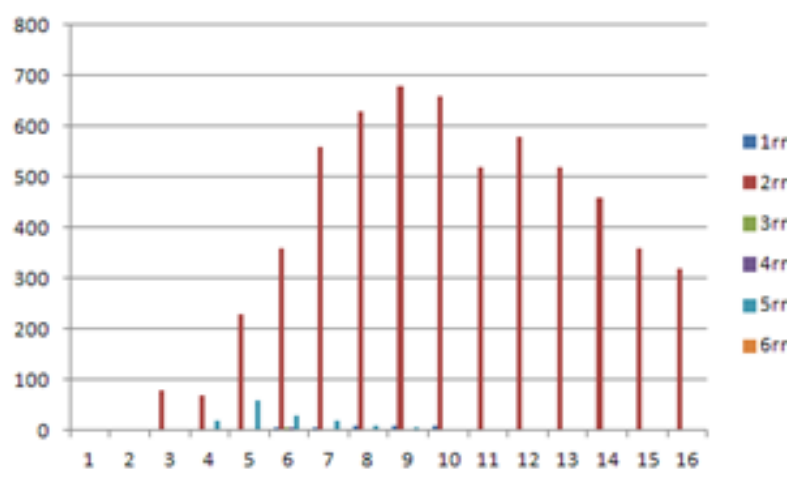

Figure 18: Loosened bolt at outstanding leg

From the above fig.20 graph it was concluded that the vibration energy at the position $2 \mathrm{rr}$ remains highest as usual as the excitation was provided near to 2 rr location. The second highest value for vibration energy was observed for position 5rr from which it was directly concluded that the damage was located at the position $5 \mathrm{rr}$

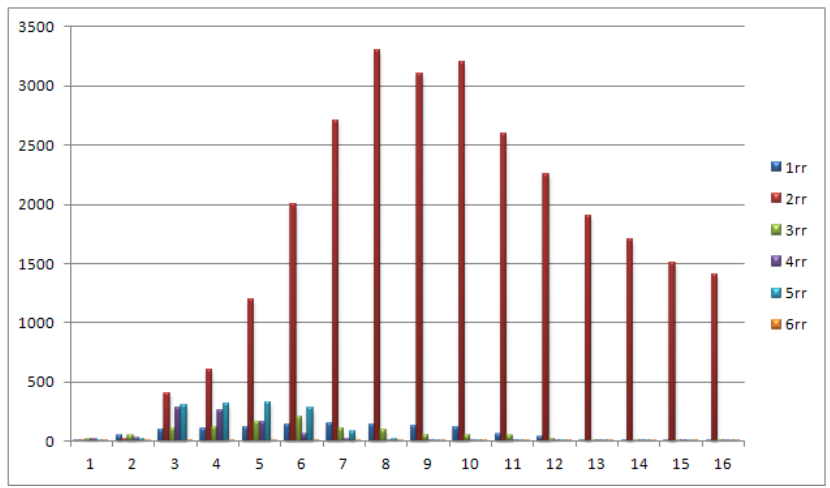

Figure 19: Loosened bolt at both connecting and outstanding leg.

Volume 5 Issue 6, June 2016 www.ijsr.net 
From the above fig. 21 it was concluded that the vibration energy at the position 2rr remains highest of all as usual. However vibration energy at all other remaining position shows a gradual increase. The increase in vibration energy is in ascending order of 3rr, 4rr and 5rr respectively. Hence from this we can conclude that the damage is present at location 4rr and 5rr since the vibration energy shows a significant increase for both these locations.

\subsection{Applications}

Focus is on gaining understanding on how to make an assessment of risk associated with structure which is excited by random loads. The service life of the structure can be increased by assessing local structural damage, indirectly helps in sustainable development.

\section{Conclusions}

The various vibration analysis of a steel frame was carried out on steel frame. The results presented in this paper highlights statistical method to damage detection and localisation on a structural steel frame. There is a scope to extend the same work on composite plate structure.

\section{References}

[1] S. W. Doebling, C. R. Farrar, M. B. Prime, A summary review of vibration based damage identification methods, The Shock and Vibration Digest, 30(2) (1998) 91- 105.

[2] M.R. Hatch : Vibration Simulation Using Matlab and ANSYS ISBN 1-58488-205-0btChapman \& Hall/CRC(2001)

[3] R. Bebiano, N. Silvestre and D. Camotim, Local and global vibration of thin-walled members subjected to compression and non-uniform bending. Journal of Sound and Vibration, 315(3), 509-535, (2008).

[4] T. Ahmed and S. Shimizu, A study of the seismic effects on a portal frame having a hole at the beam-column connection. Thin-Walled Structures, 52(March), 5360,(2012).

[5] Cilmar D. Basaglia1, Dinar R.Z. Camotim , Humberto B. Coda, GBT-Based Vibration Analysis Of Thin-Walled Steel Frames , ${ }^{11 \text { th }}$ International Conference on Vibration Problems Z. Dimitrovová et al. (eds.) Lisbon, Portugal, 9-12 September(2013).

[6] Jan Rubacek, Time Effective Transient Analysis Using ANSYS Mechanical and Matlab Simulink,(2013).

[7] Oleg V. Shiryayev.y and Joseph C. Slater, Improved structural damage identification using random decrement signatures: Application to FEM data, Structural Control And Health Monitoring, ; 15:1006-1020 ASCE (2014)

[8] Bartlomiej Blachowski, Andrzej Swiercz , and Nikos Pnevmatikos, Experimental Verification Of Damage Location Techniques For Frame Structures Assembled Using Bolted Connections,5th ECCOMAS Thematic Conference on Computational Methods in Structural Dynamics and Earthquake Engineering M. Papadrakakis, V. Papadopoulos, V. Plevris (eds.) Crete Island, Greece, 25-27 May( 2015)

\section{Author Profile}

Aneesha S Das id pursuing M.Tech. in Structural Engineering fom Sree Buddha College of Engineering affiliated with University of Kerala

Ritzy. R did Master of Technology in structural Engineering from University of Kerala in 2014. Serving as Assistant Professor, Department of Civil Engineering, Sree Buddha College of Engineering, Chenganoor P O, Allapuzha Dist. pin: 689121 